\title{
Experience of Childhood Abuse and Military Sexual Trauma Among Women Veterans with Fibromyalgia
}

\author{
Megan R. Gerber, MD, MPH ${ }^{1,2}$, Kristina M. Bogdan, BS ${ }^{3}$, Sally G. Haskell, MD, MS ${ }^{4,5}$, and \\ Erica R. Scioli, $P h D^{3,6}$
}

\begin{abstract}
'Women's Health Program, VA Boston Healthcare System, Boston, MA, USA; ${ }^{2}$ Section of General Internal Medicine, Department of Medicine, Boston University School of Medicine, Boston, MA, USA; ${ }^{3}$ Women's Health Sciences Division, National Center for PTSD, VA Boston Healthcare System, Boston, MA, USA; ${ }^{4}$ VA Connecticut Healthcare System, West Haven, CT, USA; ${ }^{5}$ Department of Medicine, Yale University School of Medicine, New Haven, CT, USA; ${ }^{6}$ Department of Psychiatry, Boston University School of Medicine, Boston, MA, USA.
\end{abstract}

\begin{abstract}
KEY WORDS: women's health; veterans; chronic pain; child abuse; trauma; fibromyalgia.

J Gen Intern Med 33(12):2030-1

DOI: $10.1007 /$ s11606-018-4594-4

(C) Society of General Internal Medicine (This is a U.S. government work and not under copyright protection in the U.S.; foreign copyright protection may apply) 2018
\end{abstract}

\section{INTRODUCTION}

Fibromyalgia syndrome is a chronic, disabling disorder characterized by widespread musculoskeletal pain often accompanied by fatigue, sleep, memory, and mood issues. ${ }^{1}$ Fibromyalgia is female-predominant with a US prevalence of $2 \%$ of the adult population $(3.4 \% \text { females and } 0.5 \% \text { males })^{1}$ and has been associated with interpersonal trauma exposure, notably abuse in childhood. Child abuse may result in long-term physiologic adaptations that promote chronic pain. ${ }^{1}$

Women veterans are a growing segment of the VA population, and among those using VA care, high levels of chronic pain and interpersonal trauma exposure prior to and during military service have been reported. ${ }^{2}$ The Veterans Health Administration (VA) uses the term "military sexual trauma" (MST) to refer to sexual harassment and/or sexual trauma experienced during the course of military service (U.S. Code, Title 38, §1720D); screening is mandatory in the VA (Table 1).

Fibromyalgia is common among women veterans. ${ }^{3,4}$ Mohanty et $\mathrm{al}^{3}{ }^{3}$ examined fibromyalgia among veterans of the wars in Afghanistan and Iraq using national VA data and found that women accessing VA care had a $4.2 \%$ prevalence of fibromyalgia. In a study of 76 women veterans, D'Aoust et al. ${ }^{4}$ found that the majority reported MST and, of these, most

Table 1 VA Military Sexual Trauma Questions

\begin{tabular}{ll}
\hline \hline Question & $\begin{array}{l}\text { When you were in the military, did you ever receive } \\
\text { unwanted, threatening, or repeated sexual attention (for } \\
\text { example, touching, cornering, pressure for sexual favors, } \\
\text { or inappropriate verbal remarks)? }\end{array}$ \\
Question & $\begin{array}{l}\text { When you were in the military, did you have sexual } \\
\text { contact against your will or when you were unable to say } \\
\text { no (for example, after being forced or threatened or to } \\
\text { avoid other consequences)? }\end{array}$ \\
\hline
\end{tabular}

Published online August 3, 2018 screened positive for fibromyalgia. This study did not use the VA-mandated screening questions. While there is limited longitudinal research on women veterans with fibromyalgia, these recent studies suggest considerable co-occurring interpersonal trauma. To our knowledge, the prevalence of childhood abuse in women veterans with fibromyalgia has not been reported. In order to better characterize interpersonal trauma exposure among women veterans with fibromyalgia seeking VA primary care, we examined child abuse history and its overlap with VA-defined MST.

\section{METHODS}

We conducted a pilot study at one VA medical center using a subanalysis of data gathered as part of a larger study that investigated women veterans' fibromyalgia care experiences in the VA. ${ }^{5}$ Participants were recruited in women's health and primary care at one northeastern VA with flyers and clinician referral. Eligibility criteria included age $<70$, absence of an active substance use disorder, and stable mental health conditions. A chart-verified diagnosis of fibromyalgia by a VA women's health/primary care provider (PCP) was required for participation. Research staff obtained informed consent, collected basic demographics, and administered posttraumatic stress disorder (PTSD) and trauma measures (the Child Trauma Questionnaire (CTQ), ${ }^{4}$ and VA Military Sexual Trauma). The institutional review board approved the study; participants were paid $\$ 50$ for completion of the entire parent study.

We examined basic demographic data including age, race, educational attainment, and employment status. Next, we summarized the CTQ and MST measures. Data were analyzed with SPSS (Version 24).

\section{RESULTS}

Twenty-two women (mean age $=51.3[\mathrm{SD}=11.65$, age range =30-76]) participated. Additional demographics, PTSD score and trauma exposure are summarized in Table 2 . The majority (90.9\%) reported experience of MST, of these $68.2 \%$ had experienced sexual assault. The mean CTQ score was 55.91 $(\mathrm{SD}=24.04)$, indicating moderate to high exposure to abuse in 
Table 2 Demographic Characteristics and CTQ/PTSD Scores by Exposure to MST

\begin{tabular}{|c|c|c|c|}
\hline & $\begin{array}{l}\text { No MST } \\
(n=2)\end{array}$ & $\begin{array}{l}\text { MST } \\
\text { Question } \\
1+(n=20)\end{array}$ & $\begin{array}{l}\text { MST } \\
\text { Questions 1 } \\
\text { and 2+ }(n=15)\end{array}$ \\
\hline Race [ref, white], $n(\%)$ & $1(50)$ & $11(55)$ & $9(60)$ \\
\hline $\begin{array}{l}\text { Educational attainment } \\
\text { [ref. college], } n(\%)\end{array}$ & $1(50)$ & $15(75)$ & $11(73.3)$ \\
\hline $\begin{array}{l}\text { Employment status } \\
\text { [ref. unemployed], } n \\
\text { (\%) }\end{array}$ & $2(100)$ & $15(75)$ & $13(86.7)$ \\
\hline $\begin{array}{l}\text { Overall mean CTQ } \\
\text { (SD) }\end{array}$ & $\begin{array}{l}46.50 \\
(3.53)\end{array}$ & $\begin{array}{l}56.85 \\
(25.06)\end{array}$ & $63.00(25.88)$ \\
\hline $\begin{array}{l}\text { Mean CTQ emotional } \\
\text { (SD) }\end{array}$ & $\begin{array}{l}7.50 \\
(3.53)\end{array}$ & $\begin{array}{l}12.40 \\
(6.46)\end{array}$ & $13.86(6.39)$ \\
\hline Mean CTQ SA (SD) & $\begin{array}{l}18.50 \\
(7.78)\end{array}$ & $\begin{array}{l}12.10 \\
(7.39)\end{array}$ & $13.07(7.26)$ \\
\hline $\begin{array}{l}\text { PTSD PCL mean score } \\
\text { (SD) }\end{array}$ & $\begin{array}{l}35.50 \\
(23.3)\end{array}$ & $\begin{array}{l}56.55 \\
(16.65)\end{array}$ & $62.60(11.13)$ \\
\hline
\end{tabular}

childhood; sexual abuse and emotional neglect were commonly endorsed. Women who endorsed both MST items (Table 1) had higher PTSD and CTQ scores.

\section{DISCUSSION}

Women Veterans with fibromyalgia have considerable histories of child abuse, and those with greater MST exposure endorsed higher degrees of both child abuse and PTSD severity. The developmental timing of trauma exposure may impact the neurobiological adaptations that enhance long-term risk for PTSD and somatic conditions, ${ }^{6}$ like fibromyalgia. As MST and PTSD inquiry is mandatory in the VA, examining child abuse prevalence among women with fibromyalgia by MST screening category yields important information that may enhance therapeutic interventions.

This small study only evaluated women accessing VA services; these findings may not generalize to non-user women veterans. Finally, data are cross-sectional and do not allow evaluation of the temporal relationship of child abuse to fibromyalgia, or of fibromyalgia diagnosis to military service.

In summary, this study expands our understanding of trauma exposure, notably during childhood, in women veterans with fibromyalgia. These data underscore recommendations for an interdisciplinary biopsychosocial approach to fibromyalgia care ${ }^{1}$ and may support the use of trauma-focused treatment along with symptom management. Additional work is needed to determine the most effective interventions for women veterans with fibromyalgia in primary care settings.

Corresponding Author: Megan R. Gerber, MD, MPH; Women's Health Program VA Boston Healthcare System, 150 South Huntington Avenue, PC 11/WHC, Boston, MA 02130, USA (e-mail: megan. gerber@va.gov).

Funding Funding for this project was provided as part of an operational quality initiative through Women's Health Services, Veteran's Health Administration. The research described here was also supported in part by the Department of Veterans Affairs, Veterans Health Administration, Rehabilitation Research and Development Service (Award Number 1IK2RX000704-01A2).

Compliance with Ethical Standards: The institutional review board approved the study.

Conflict of Interest: The authors declare that they do not have a conflict of interest.

Disclaimer: The views expressed in this article are those of the authors and do not necessarily represent the position or policy of the Department of Veterans Affairs or the United States Government.

\section{REFERENCES}

1. Borchers AT, Gershwin ME. Fibromyalgia: a critical and comprehensive review. Clin Rev Allergy Immunol. 2015;49(2):100-151.

2. Haskell SG, Papas RK, Heapy A, Reid MC, Kerns RD. The association of sexual trauma with persistent pain in a sample of women veterans receiving primary care. Pain Med. 2008;9(6):710-717.

3. Mohanty AF, Helmer DA, Muthukutty A, et al. Fibromyalgia syndrome care of Iraq- and Afghanistan-deployed Veterans in Veterans Health Administration. Journal of rehabilitation research and development. 2016;53(1):45-58.

4. D'Aoust RF, Rossiter AG, Elliott A, Ji M, Lengacher C, Groer M. Women veterans, a population at risk for fibromyalgia: the associations between fibromyalgia, symptoms, and quality of life. Mil Med. 2017;182(7):e1828e1835.

5. Scioli-Salter ER, Smith BN, McSheffrey S, et al. Self-efficacy for adoption and maintenance of exercise among fibromyalgia patients: a pilot study. American Journal of Lifestyle Medicine. Epub 12 December 2017.

6. Scioli-Salter ER, Johnides BD, Mitchell KS, Smith BN, Resick PA, Rasmusson AM. Depression and dissociation as predictors of physical health symptoms among female rape survivors with posttraumatic stress disorder. Psychol Trauma. 2016;8(5):585-591. 